\title{
De la vida de sant Onofre valenciana i anònima, de principis del XvI, a la recreació d'Onofre Salt (Barcelona, 1620) ${ }^{1}$
}

\author{
Vicent Josep Escartí Soriano \\ Universitat de València \\ vicent.j.escarti@uv.es
}

Recepció: 22/01/2017, Acceptació: 27/03/2017, Publicació: 22/12/2017

\section{Resum}

La devoció en terres de parla catalana a l'anacoreta sant Onofre es troba bastant difosa i compta amb nombrosos testimonis. Entre els literaris, en destaquen dos. Un, en català, publicat a principis del segle XVI, a València — anònim i amb clares evidències de ser un treball que recull textos elaborats en estadis anteriors-, i l'altre publicat a Barcelona — malgrat que obra del valencià Onofre Salt—, del 1620, i en castellà. Ens proposem veure les diferències entre l'un i l'altre $i$, encara, els punts en comú de dos textos devocionals hagiogràfics que es troben als extrems de la cruilla de l'edat moderna: de l'edat mitjana al Renaixement, el primer, i ja al barroc, el segon.

Paraules clau

sant Onofre; hagiografia; segle XV; segle XvII; Onofre Salt

\begin{abstract}
From the Valencian anonymous life of St. Onophrius at the beginning of the sixteenth century to the recreation of Onofre Salt (Barcelona, 1620)

The devotion to the anchorite Saint Onophrius in Catalan-speaking lands is quite wide-
\end{abstract}

1. Aquest treball forma part de les línies de recerca del Grup d'Investigació de la Universitat de València LLiCValSOR (GIUV2013/062) i, encara, se situa en la matriu dels projectes de l'Institut Superior d'Investigació Cooperativa IVITRA [ISIC-IVITRA] de la Generalitat Valenciana (ISIC/012/042) i del PrometeoII/2014/018. Per altra banda, el treball està inserit en el projecte UV-INV-AE14-269762. 
spread and has numerous witnesses. Among the literary ones, two stand out. One in Catalan, which is anonymous and was published in Valencia at the beginning of the sixteenth century with clear evidence of being a work that includes texts elaborated in previous stages, and another published in 1620 in Barcelona in Spanish despite being a work of the Valencian Onofre Salt. This article examines the differences between both and the points in common of the two hagiographic devotional texts that are at the end of the crossing of the modern age: the first from the Middle Ages to the Renaissance, and the second that is already in the Baroque period.

\section{Keywords}

Saint Onophrius; hagiography; fifteenth century; seventeenth century; Onofre Salt

\section{Preliminar}

Recentment he pogut acostar-me, en diferents ocasions (Escartí 2014, 2015) a la Vida de sanct Honofre, conservada actualment en exemplar únic postincunable a la Biblioteca de la Universitat de València $(\mathrm{CF} / 3(01)$, el qual, malgrat que pot semblar una peça d'hagiografia medieval quasi oblidada, conté elements ben interessants i ens demostra, entre altres coses, com s'anaven construint aquesta mena de textos, per acumulació i ampliació, al llarg dels segles. En concret, perquè, en aquest sentit, la transmissió del text sobre sant Onofre és bastant clara, com ja va saber evidenciar Curt Wittlin, fa anys (1995: 103-18). Per altra banda, cal apuntar que el text anònim ha gaudit sempre de l'interès més o menys específic per part d'alguns estudiosos i erudits — començant, al segle xvıII, per Lluís Galiana o Vicent Ximeno, com veurem-, que han aportat dades per poder conèixer-lo millor; però també, més recentment, amb estudis solvents — com el ja esmentat, de Wittlin (1995) — i, sobretot, el de Valldecabres (2004), al qual hauríem d'afegir una edició facsímil (2004) i la més recent transcripció i edició que hem portat a terme nosaltres, en dues maneres diferents (Escartí 2014, 2015). 
Per la seua banda, la Historia de la maravillosa vida, angélica conversación y preciosa muerte del glorioso san Onofre, rey, anacoreta y confessor, obra del valencià Onofre Salt, publicada a Barcelona el 1620, no ens consta que haja rebut atenció en cap monografia o estudi, més enllà d'alguna referència aïllada que ja reportarem.

Aquesta diferència prou que evidencia la naturalesa diversa dels materials de què parlem: si el primer és una mostra remarcable d'impremta postincunable $\mathrm{i}$ en la nostra llengua, i s'ha de posar en contacte amb el món medieval del que prové i d'on es nodreix, en un entorn sens dubte influenciat per la producció hagiogràfica d'homes com Roís de Corella o Miquel Peres; ${ }^{2}$ en el cas del segon, el treball elaborat per Salt no passa de ser una mostra més d'hagiografia barroca en castellà —un gènere que compta amb centenars i centenars d'exemples.

No obstant aquestes diferències, i d'altres, volem remarcar algunes qüestions — ni que siga de passada, en alguns casos- per tal de veure com, entre la Vida de sancto Honofre — anònima i valenciana - i el treball del valencià Onofre Salt — una vida de sant Onofre amb moltes altres pretensions - , hi ha, però, un lligam ben clar que ens permet parlar, encara, de contacte directe entre el món medieval i el del barroc, entre el text valencià de principis del xvı i el treball literari del prior servita del convent barceloní del Bon Succés.

\section{Algunes qüestions sobre l'anònima Vida de sant Honofre}

Cal destacar que va estar Vicent Ximeno, a mitjans del XvII, el primer a donar notícies sobre aquesta obra anònima, malgrat que de manera una mica confusa: parlant de Lope de la Roca Alamany [sic] «valenciano», explica que «compuso en su lengua nativa un libro» que hauria estat citat per sant Lluís Bertran i que Ximeno diu haver vist i que portava per títol «La vida de sant Honorat. Impresso en Valencia 1495, en 4. El nombre del autor está a lo último» (Ximeno 1749, II: 375). Afegia, tot seguit, que «después se sigue otra obra de otro autor anónimo, intitulada La vida de sant Onofre, confessor e hermità, escrita en idioma valenciano, y es de la misma impresion que la primera» (Ximeno 1749, II: 375). Aquesta referència de Ximeno correspon, sens dubte, al títol de la vida onofrina que apareix a la primera pàgina de l'edició que ens ocupa — no la que apareix a la portada - i que, per tant, també hauríem de datar, seguint Ximeno, el 1495.

Tanmateix, abans de Ximeno, Onofre Salt — de qui parlarem tot seguit-, en redactar el pròleg de la seua vida de sant Onofre, i en parlar dels autors que han escrit sobre el sant anacoreta, i per al que ens interessa ara, ací, a més d'es-

2. Sobre la producció hagiogràfica d'aquests dos autors cal veure, entre d'altres, Arronis (2015a, 2015b, 2016), Martínez Romero (2012), Martos (2000), López Quiles (2007), López Quiles i Puig Gisbert (2014) i Roís de Corella $(2013,2014)$. 
mentar fonts manuscrites que veurem més endavant, fa referència a com ell, «de mochacho e guardado perpetuamente un libro anónimo de la vida de mi santo, impresso en lengua valenciana y en Valencia a veynte de deziembre 1501" (Salt 1620: Prólogo s.p.). Aquest exemplar seria, doncs, una segona edició de l'esmentat anteriorment, si acceptem com a correctes les dades ofertes per Salt. Unes dades que no quadren, tampoc, amb les de l'exemplar que es conserva a la BUV i que serveix per a fer el present estudi.

Cal dir, per altra banda, que, si seguim les pistes de la Vida de sant Honorat citada per Ximeno, Serrano Morales (1898-99: 498-500) ja va deixar clar que l'exemplar citat per Ximeno havia estat realment imprès el 1495 —alguns, per distracció, l'havien datat del 1485-; però no va dir res sobre la vida de sant Onofre que l'acompanyava en el volum de Vinalesa. ${ }^{3}$

Hem d'afegir, encara, que existeix una edició de la Vida de sant Honorat, impresa a València, el 1513, per Joan Jofre, els tipus gràfics de la qual són en tot molt semblants — per no dir idèntics - als de la Vida de sant Onofre que ens ocupa. Més encara, si tenim en compte que Serrano Morales afirma que la vida de l'anacoreta Onofre -l'exemplar de la BUV, que és el mateix que usem nosaltres - va eixir de les premses de Jofre, atès que els seus tipus són els mateixos exactament dels de la Vida de sant Vicent Ferrer, de Miquel Peres (València, 1510) i dels de La història de Joseph, de Joan Roís de Corella, que tampoc porta nom d'impressor; i així, afirma:

Por la identidad de los caractéres tipográficos, abreviaturas, etc. de dicha obra y los que se usaron en las dos siguientes [les vides sant Onofre i de Jacob], que carecen de lugar, fecha y nombre de impresor, creemos que también estas feuran estampadas por Jofré y probablemente hacia el mismo año 1510. (Serrano Morales 1898-99: 227-228)

Una confusió entre la data del 1510 proposada per Serrano Morales i la del 1501 que ens aporta Salt — possiblement per errada clarament tipogràfica—, ja se'ns fa més comprensible. El que no sabem, però, és d'on provindria la data del 20 de desembre que apunta el prior servita.

En qualsevol cas, més enllà del problema de la datació de la impressió, el ben cert és que, tornant al segle xviII, fra Lluís Galiana, el 1763, demanava la reedició de la Vida de sant Onofre, en la cèlebre carta que adreçà a Carles Ros i que aquest publicà al seu Diccionario, un any després. Tot i l'expressió una mica confusa d'aquelles paraules del frare d'Ontinyent, s'inferiria una possible atribució d'autoria del nostre text a Miquel Peres. Així, Galiana diu: «Este mismo autor [Mi-

3. Serrano Morales (1898-99: 500) afirma que l'exemplar del Col-legi del Corpus Christi, del qual reprodueix facsimilarment el colofó, i on l'alemany Lope de la Roca n'és sols l'impressor -i no l'autor-, anava seguit per un Arte de bien confessar y de bien oir confessiones..., de Pedro Ciruelo, que no porta any ni data d'impressió. 
quel Peres] tradujo en valenciano la vida de santa Catarina de Sena que escrivió en su Crónica san Antonino de Florencia, la qual se publicó en Valencia, con otra anónima de San Onofre, escrita en lemosín, año 1498» (Galiana 1764: s.p.). Les preguntes que es desprenen d'aquesta informació serien, entre altres: es publicà la Vida de Sant Onofre juntament amb l'altra, com sembla inferir-se de les paraules de Galiana? O la va traduir Peres, juntament amb la vida de la santa Caterina esmentada? D'on va traure Galiana aquelles informacions? Es referia Galiana a la Vida de sancta Catherina impresa per Cristòfor Cofman a València (1499) o a la Vida de la seràphica Catherina de Siena, impresa per Jofre (1511)? Les dades aportades les invalida el fet que en un altre lloc — com ja indicà Ribelles Comín (1929: II, 31) _ Galiana es confon, en oferir dades novament? Per altra banda: respecte a les diferències de datació que esmenta fra Galiana, tenen a veure aquestes variacions amb les suposades dues edicions de la vida onofrina que referencia Marià Aguiló (1923: 324), de la segona de les quals, en vuitè, no hem sabut trobar cap rastre?

Si Miquel Peres les va «traduir» totes dues — com també interpreta Josep Vilarroya (1804: 197-198) de la indicació de Galiana-, potser la clau serà veure'n les fonts i comparar el text referit a sant Onofre amb l'altre que conté la vida de santa Caterina, si és el cas, i fer una comparació sistemàtica de la llengua i l'estil emprats en un i en l'altre. Una tasca que, ara com ara, no podem fer ací, però que, sens dubte, seria de gran ajuda. Sí que apuntarem, si més no, que l'estil de l'escrit que ens ocupa té ben poc de corellà, tret d'algun breu fragment que, potser, presenta alguna voluntat més literària, per dir-ho així.

Uns anys més tard, just Pastor Fuster (1827, I: 297) ja va descriure l'exemplar que es conserva a la BUV i que va ser propietat d'Onofre Soler, el qual el va llegar a la Universitat de València, on encara es conserva (sign. CF/3-1), sense aportar-hi res més.

Ara com ara, la Vida de sanct Honofre se la suposa també impresa per Jordi Costilla, el 1502 (Gisbert i Ortells 1992: 453), tot i que abans, com hem vist, ha tingut altres datacions i filiacions d'impressor, en les quals no entrarem (Valldecabres 2004: XV-XVI). I encara en té d'altres posteriors, entre les quals mereix consideració la més recent, de Valldecabres (2004: XV-XVII), que accepta el 20 de desembre de 1501, a partir de la informació que recull Onofre Salt, al pròleg de la seua ja esmentada Historia de la maravillosa vida, angélica conversación y preciosa muerte del glorioso san Onofre, rey, anacoreta y confessor, del 1620. J. L. Canet la situaria al voltant del 1500, i obra de l'impressor Alfonso de Orta, sense dir, però, on es fonamenta (Canet 2005).

És per això que ens decantem, ara com ara, per datar aquesta edició en els primers anys del XVI, sense atrevir-nos a més, fins que no es constatin completament les dades de què disposem i, també, perquè, al remat, la concreció en l'any de la seua impressió exacta no aportaria molta més informació que la dada per ella mateixa.

Sense insistir més en el problema de l'autoria del resultat final de la Vida de sanct Honofre, la datació de la impressió i, encara, el nom de l'impressor, allò 
que cal destacar és que es tracta d'un text valencià i que el seu impressor - per les diferents errades que introdueix a l'edició- ben probablement era d'origen castellà o acostumat a treballar amb textos en aquella llengua. Per altra banda, cal assenyalar que la seua difusió degué ser bastant àmplia, tenint en compte la devoció que assolí el sant als segles XVI i XVII, i més encara pel fet que ens consta com Onofre Salt el cità a la seua versió de la història de sant Onofre, cosa que indica ben a les clares que alguns exemplars de l'opuscle valencià continuaven encara en ús, més de dos-cents anys després de la seua estampació.

També cal remarcar ara que, si el possible autor, el possible editor i el possible any d'edició encara demanen informació més detallada, podem afirmar que sabem molt més de les fonts i del recorregut de l'obra, entre sant Pafnuci — primer autor de la vida de sant Onofre- i l'edició valenciana del Xvı. En efecte, sabem (Valldecabres 2004, XIX-XX) que el volumet imprès al cap i casal del regne de València deriva directament del ms. 13 de la Biblioteca de Catalunya (BITECA manid 1299) o d'una còpia d'aquest, que hauria fet d'intermediària. Ara bé: mentre que el manuscrit esmentat presenta trets del català oriental, la nostra edició és pulcrament occidental. Del manuscrit no ens cal aportar massa, ací; però, és ben conegut, i sembla que va ser fet copiar pel rei Martí l'Humà per tal de donar-lo als monjos de la cartoixa valenciana de Vall de Crist (Valldecabres 2004, XIX). Seria fruit, sens dubte, de la devoció que va assolir el sant, en terres de la Corona d'Aragó, durant els segles XIV i XV (Barniol 2008). Es trobava encara al XVII, a Vall de Crist, i el prior Onofre Ripoll li comunicà la seua existència a Salt (Salt 1620: Prólogo s.p.). Per una altra part, convé assenyalar que el manuscrit ha estat recentment editat, en dues ocasions: per Hernández Serna (1993-1995), en primer lloc, amb transcripció paleogràfica no exempta d'algunes errades, però que s'acompanya, per fortuna, d'una reproducció facsímil; i en l'obra de Valldecabres (2004), que el confronta a doble columna amb l'edició valenciana anònima del text onofrí i que no esmenta l'edició anterior suara citada. Cal indicar que el volum de Valldecabres (2004) conté, a més, l'única edició actual del text de la Vida de sanct Honofre. ${ }^{4}$ Per altra banda, a començaments del 2014 vam elaborar una edició de la mateixa Vida de sanct Honofre, de caràcter molt particular, atès que es tracta d'una edició privada, amb només un centenar d'exemplars, i és per això que, poc després, ens decidírem a publicar-la en una revista electrònica, amb molt major abast (Escartí 2014).

Encara, en referència a les fonts del text valencià, si bé no totes es troben identificades plenament, almenys comptem amb prou detalls per aproximar-nos-hi amb bastantes probabilitats d'encert en molts dels casos. I això, encara, ens permet veure'n l'estructura del text, com ja van destacar Wittlin (1995) o Hernández Serna (2002). De fet, a la Vida de sanct Honofre hi ha cinc o sis

4. Se'n va anunciar una altra, a cura del mateix Valldecabres i per a la casa editorial Vicent García Editores, que hauria superat, certament, l'abast local de la primera, tot i que hauria caigut, però, en l'àmbit més restrictiu encara de la bibliofília. 
parts que corresponen a diferents estadis de la seua composició i que ens aporten clarament dades sobre la filiació de cadascuna d'elles. Així, el nucli originari de la Vida onofrina seria la versió elaborada per Pafnuci al segle IV o principis del v (capítols VII-XI de la nostra edició), que seria redactada en grec i traduïda posteriorment al llatí, i on es conté la vida del sant i, més breument, la d'altres homes eremites del desert. També degueren afegir-s'hi els fragments de la invenció del cos sant i el seu trasllat a Bohèmia (capítols XII-XIV). Aquesta part, clarament imbuïda de l'esperit de les croades, i que mostra la gran passió d'aquells anys per les relíquies, segurament va ser afegida als segles XII o XIII.

En algun moment inconcret, aquest text degué arribar a Itàlia i, llavors, seria reelaborat, tot afegint-hi alguns episodis sobre la devoció a sant Onofre en les terres nord-italianes (capítols XV-XVI), segons que apunta Wittlin (1995: 110), el qual també indica que la part que «imagina» una vida anterior a la de l'eremitisme i en què Onofre se'ns presenta, primer, com a príncep i, després, com a rei d'Hongria, títol al qual renunciaria per dedicar-se a la vida eremítica (capítols I-VI), seria un afegit del traductor català (Wittlin 1995: 110), el qual hauria begut des del llatí o des de l'italià d'alguna versió de les Vitae Patrum o de l'obra de Domenico Cavalca, a l'hora de treballar la Vida de sant Onofre, com sembla deduir-se de certs fragments (Wittlin 1995: 114). Aquest traductor degué incorporar també el miracle esdevingut a Barcelona, tal com es conserva al ja esmentat ms. 13 (capítol XVII).

Després, en l'edició valenciana —claríssimament descendent del manuscrit del rei Martí, com ja hem dit i com també assenyala Wittlin (1995: 110) i remarca Valldecabres (2004) — s'adjuntaran alguns miracles locals i un parell més, situats respectivament a Girona i a Montpeller (capítols XVIII-XXII), que clouen, així, el periple d'aquesta versió del text que es presenta com a suposadament biogràfic — de la vida terrenal i de la que, des de l'altre món, encara, protagonitza el sant-, i que es tanca amb una oració que sens dubte estava destinada a fomentar que els fidels s'aclamassen al sant ermità.

Caldria indicar també — ni que siga de passada — que, vinculada a la Legenda aurea de Giacomo da Varazze, hi funcionà, paral-lelament des del segle Xv, almenys, una altra versió de la vida onofrina emparentada clarament amb la nostra. Aquesta versió, publicada per primera vegada al Flos sanctorum del 1490-96, recull, en realitat, alguna versió més antiga derivada del relat de Pafnuci, estrictament, i sense l'afegit del retrobament del cos sant i, encara, sense la vida principesca d'Onofre. Aquesta versió només ha estat editada recentment (Pastor Briones 2012) i, en un treball posterior, caldria veure clarament els punts de contacte amb la que ens ocupa.

Finalment, en referència a la impressió de principis del xvI, hem d'esmentar la portada que presenta l'edició valenciana. De fet, aquesta ja va estar reproduïda a la Bibliografía valenciana de Ribelles Comín (1929: II, 30-33) i, abans i tot, al conegut treball sobre les impremtes de Serrano Morales (1898-1899: 228). Si alguna cosa crida l'atenció d'aquella xilografia és la combinació d'elements sàviament disposats, que la converteixen en un retaule en miniatura — com ja hem comentat en algun altre lloc (Escartí 2014: 180-181)—; però, també, l'er- 
rada quasi incomprensible que presenta l'ús de l'abreviatura d'origen llatí — però de desenvolupament castellà- en una obra tan netament valenciana i d'un moment encara tan primerenc del segle Xvi: sancto, un detall que només seria explicable si l'impressor era d'aquella nació o havia treballat allà o acostumava a treballar en aquella llengua o si, potser, la portada en conjunt va estar elaborada per a una versió en espanyol, que ara com ara no ens consta, tot i que aquesta forma abreujada sembla que també s'usava sovint en textos catalans.

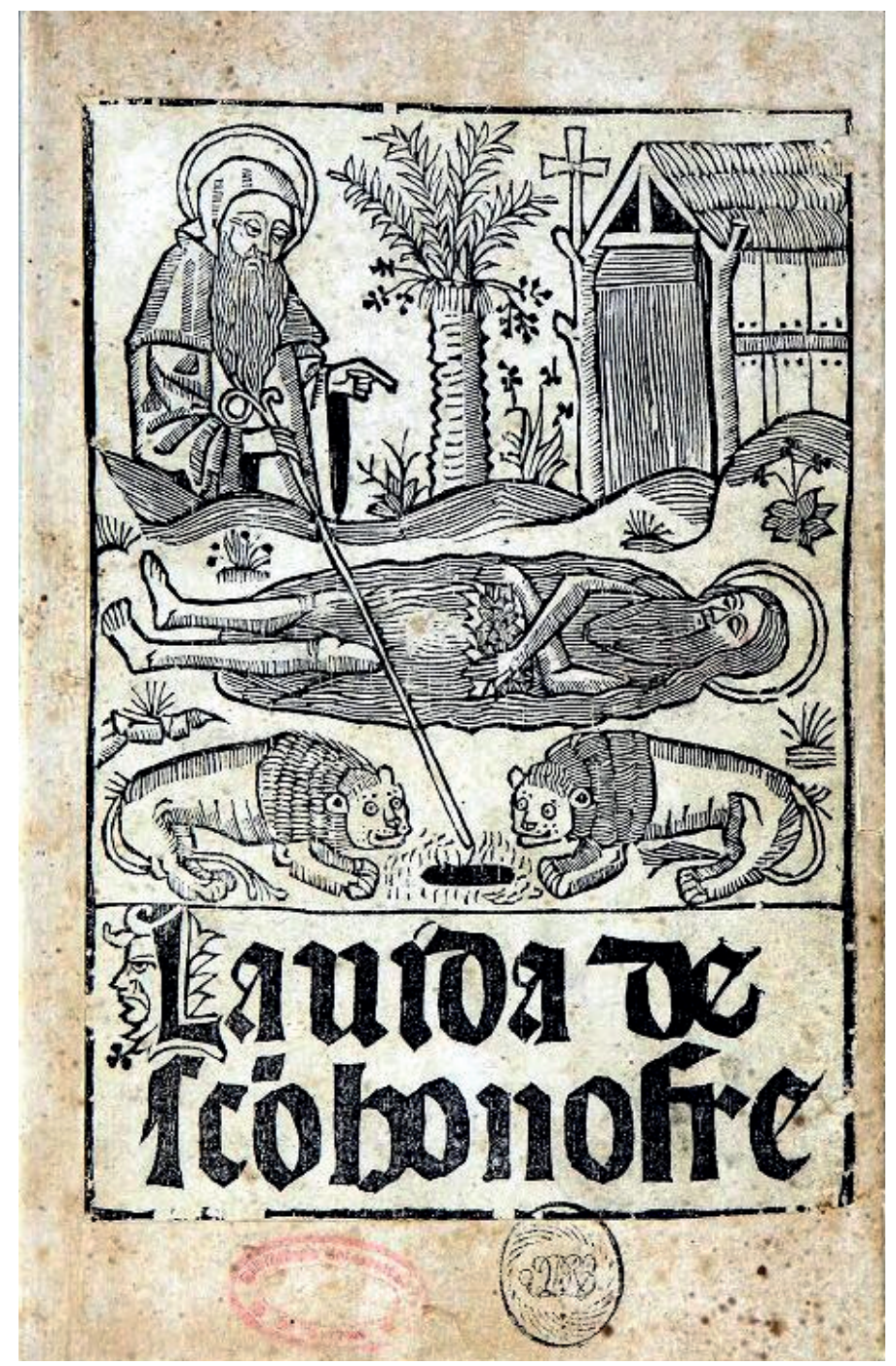

Figura 1.

Portada xilogràifica de La vida de sanct Honofre. Biblioteca de la Universitat de València, sign. CF/3(01). 


\section{Onofre Salt i la Historia de la maravillosa vida, angélica conversación y preciosa muerte del glorioso san Onofre, rey, anacoreta y confessor}

Són poques les notícies que ens han pervingut sobre Onofre Salt. En principi, ens consta que va professar, el 1597, com a trinitari (Rodríguez 1747: 356), a València, i, més tard — possiblement atret pels moments fundacionals d'un nou orde religiós_- passà al dels Servents de la Mare de Déu —o servites_ i arribà, després d'ocupar altres càrrecs (Rodríguez 1747: 357), a ser prior del convent del Bon Succés de Barcelona, on degué morir, el 1626 (Lorente 2014: 152). La seua activitat literària devia ser més abundosa del que ara sabem, ja que l'escriptor aragonès Vicencio Blasco de Lanuza, que el tractà en persona (Blasco de Lanuza 1622, I: Prólogo) i no s'està de fer-lo, fins i tot, aragonès (Blasco de Lanuza 1622, I: 563), segurament per la seua vinculació al convent servita de Cuevas de Cañart (Blasco de Lanuza 1622, I: 444), afirma que —a més dels dos llibres que tot seguit referirem - «ha compuesto también y impresso otros tratados y tiene para imprimir algunos» (Blasco de Lanuza 1622, I: 563).

Onofre Salt, en efecte, arribà a publicar dos volums, a Barcelona: l'Epitome de la milagrosa fundación de la sagrada orden mendicante de los Siervos de Nuestra Señora (Barcelona, Joan Amelló 1611) i la Historia de la maravillosa vida, angélica conversación y preciosa muerte del glorioso san Onofre, rey, anacoreta y confessor (Esteve Liberós 1620). Encara, consta que va deixar manuscrita una Vida, conversación y muerte del bendito padre fray Francisco Davón, valenciano, de la orden de la Santissima Trinidad, que hauria escrit seguint les instruccions dels seus superiors, mentre habitava al convent trinitari del Remei, a València, el 1605 (Rodríguez 1747: 357). A més, segons que ell mateix ens informa en una nota marginal de la seua vida de sant Onofre, redactà un «sermón que al velo de soror Joana Bautista Salt prediqué en Santa Caterina de Sena de Valencia» (Salt 1620: 109v.). El bibliògraf valencià Josep Rodríguez «també trinitari, com el mateix Salt en els seus orígens» no diu res d'aquest darrer sermó, si bé li dedica paràgrafs generosos i s'endinsa en la defensa faccil de la seua valencianitat - reconeguda per l'autor en les portades dels seus llibres, on afirma ser valenciano-, contra una pretesa filiació aragonesa ja citada (Rodríguez 1747: 357), i no va esmentar - atès que això no era de cap relleu en aquell moment-, el fet pel qual se'l recorda actualment, a Sagunt: va ser qui va donar a la comunitat de monges servites d'aquella ciutat la imatge de la Mare de Déu del Bon Succés (Ferri Chulio 1983) que encara es conserva allà actualment i que n'és la patrona, fet que remarcaria el seu interès per estendre l'advocació amb què s'emparava el convent d'on era prior i, segons sembla, per la seua vinculació a Sagunt, on hi hauria estat en diferents ocasions. 


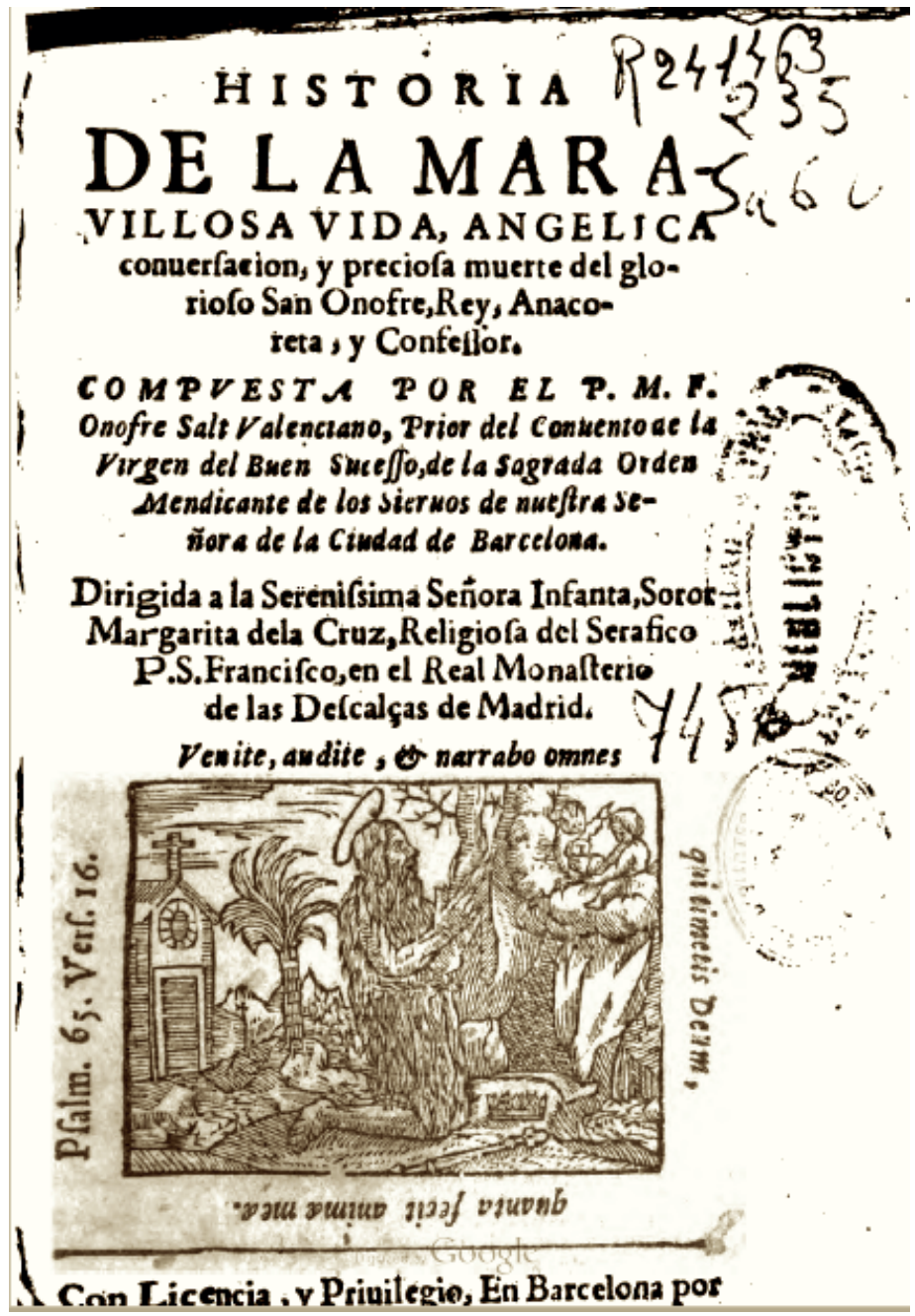

Figura 2.

Portada de la Historia de la maravillosa vida, angélica conversación y preciosa muerte del glorioso san Onofre, rey, anacoreta y confessor (Barcelona, Esteve Liberós 1620).

Pel que fa a la vida de sant Onofre que va fer estampar, el 1620 — com ja hem dit, a Barcelona_, resulta bastant evident que, al darrere d'aquella seua devoció pel sant de qui portava el nom, hi havia una intencionalitat clarament política: el volum, de més de 400 pàgines, s’adreça a la infanta Margarita — «soror Margarita de la Cruz, religiosa del seráfico padre san Francisco, en el Real Monasterio de las Descalças de Madrid», com es diu a la portada-, la qual 
era filla de l'emperador Maximilià II d'Àustria i de Maria d'Àustria i Portugal, de manera que era neboda i néta de Carles V i, doncs, tia de Felip II d'Aragó i III de Castella. Va nàixer a Viena, el 1567, i moriria el 1633, després d'haver professat a Madrid, al convent de les clarisses conegut com las Descalzas. Va anar a Madrid, acompanyant sa mare, el 1582 — quan aquesta se'n tornà, des d'Àustria - i va estar a punt de convertir-se en reina, si hagués acceptat el matrimoni amb el seu cosí Felip I d'Aragó i II de Castella, al qual va rebutjar. La seua fama de dona religiosa degué ser important i Juan de Palma, després de la mort d'aquella, en va elaborar una profusa biografia, per encàrrec del rei Felip III d'Aragó i IV de Castella, que es va publicar el 1653.5 Era, per tot això, una dama de la més alta noblesa i influència a la cort de Madrid $i$, per tant, podia resultar una destinatària ideal per tal de promocionar l'orde dels servites, de la qual era prior fra Onofre Salt.

L'autor, per això, després dels papers preliminars de la seua obra —entre els quals trobem la llicència d'impressió, en català, concedida pel duc d'Alcalá com a lloctinent i capità general del Principat de Catalunya ${ }^{6}$ - redactà una densa dedicatòria, de vuit pàgines, en què s'esforça per mostrar els avantpassats de la casa d'Àustria que havien entrat en religió — com la mateixa Margarita de la Cruz- i com havien afavorit aquells les seues cases religioses i els ordes de què formaven part. I l'excusa per dedicar-li aquella vida onofrina era clara: la «historia de un rey como san Onofre (...), por haverlo sido de Ungría — según la mejor opinión-, pienso tiene parte su sereníssima sangre, eredando, como aquel reyno, la decendencia de tan grande santo» (Salt 1620: A la serenissima señora... s.p.).

5. El text de Juan de Palma, Vida de la serenissima infanta sor Margarita de la Cruz, religiosa descalza de Santa Clara (Madrid, Imprenta Real 1636), encara es tornaria a publicar a Sevilla, per Nicolás Rodríguez de Ábrego, el 1653.

6. La llicència inclosa al volum porta data del 22 de maig de 1620. Segons Josep M. Madurell (1955: 381-382) hi hagué un "permís concedit pel lloctinent de Sa Majestat, duc d'Alburquerque, a fra Onofre Salt, OSM., per a publicar l'Història [sic] de la vida y mort del gloriós Sant Onofre, estampada en aquell mateix any a la nostra ciutat comtal». En aquell article, Madurell havia declarat que «avui ens ocuparem tan sols dels permisos atorgats per a estampar algunes obres escrites en la nostra llengua vernàcula». Per una altra banda, en nota (18) al primer fragment que hem citat ací, Madurell remet a l'ACA i ens dóna com a data del permís el 22 de maig de 1620 — de forma que s'acorda amb la llicència inclosa en el volum de Salt-i, després, remet en una nova nota (19) a la referència bibliogràfica de Vicent Ximeno, en què es citaria la nostra obra; però, evidentment, en castellà. De forma que el més probable és que Madurell es deixàs portar pel títol que apareix a la mateixa llicència — «un llibre intitulat Història de la vida y mort del gloriós sant Onofre»—i que no n’arribàs a veure'n cap exemplar, per advertir que l'edició del text era en castellà. 


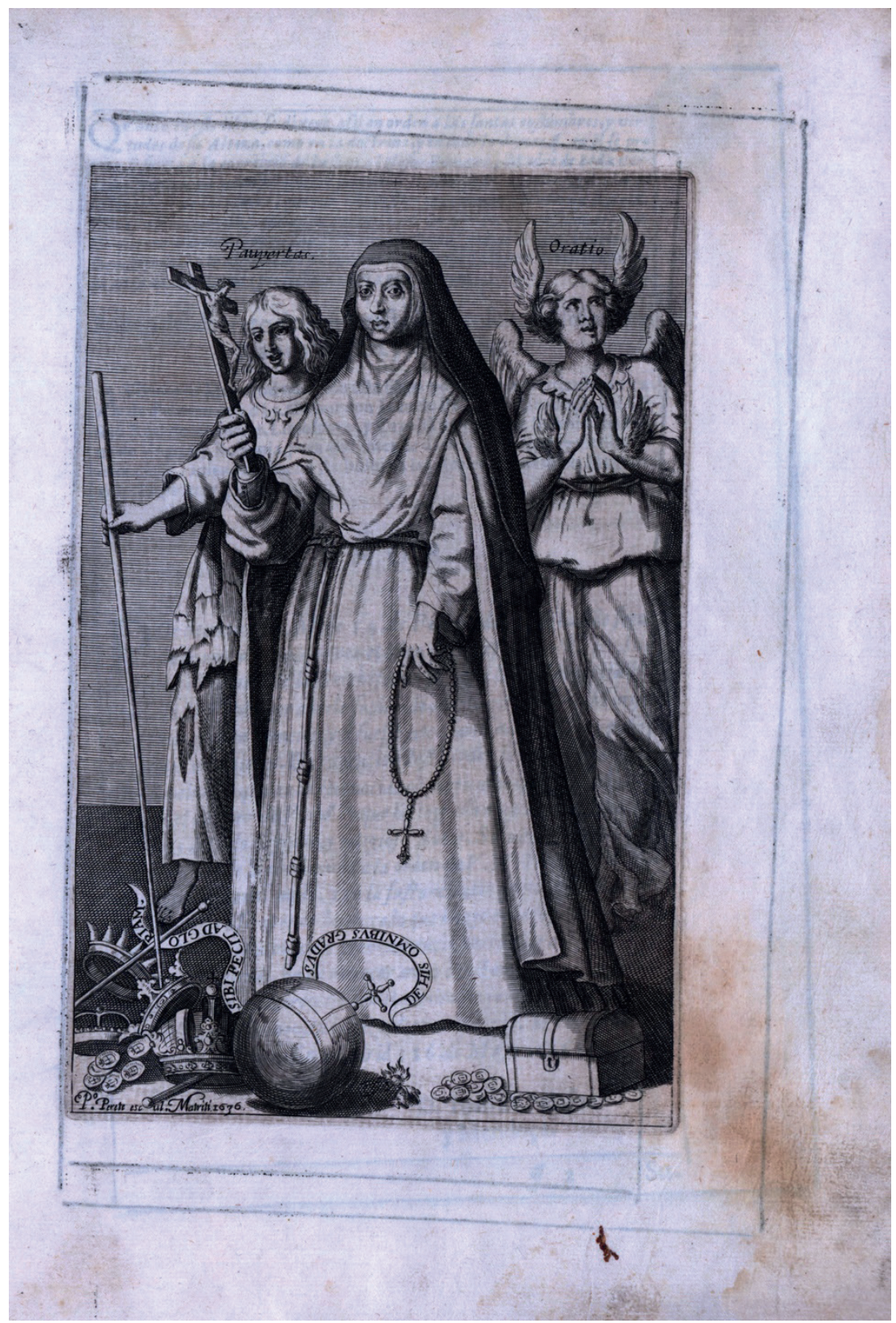

Figura 3.

Sor Margarita de la Cruz, segons el gravat que apareix a l'obra de Juan de Palma (1636). 
L'apartat següent de l'obra de Salt és una clara defensa del seu mateix treball, que segurament havia rebut crítiques abans de ser publicat, per part dels qui l'haurien llegit, probablement per ocupar-se de la vida d'un sant tan reculat en el temps. I això es veu ja en el mateix títol: Prólogo al lector, donde con historias graves, antiguas y raras y doctrina muy calificada responde el autor a las objeciones que pueden oponer, los poco leydos, a su verdadera historia. De fet, en aquest pròleg, Salt tracta de demostrar que els "historiadores de cosas antiguas y prodigiosas», quan es troben amb dubtes, per a aquells, «el remedio es leer libros viejos»: és a dir, utilitzar les fonts per tal de saber-ne més. I tot seguit passa a enumerar i a explicar qüestions d'història sagrada que semblaven impossibles d'esbrinar, però que s'han resolt, com ara: el nombre dels fills d'Adam, el pes d'unes joies de Rebeca, de què aprofitaren les banyes del cabrit del sacrifici d'Abraham, el nombre de fills d'Israel, els de la tribu de Judà, el dels «gitanos» — per egipcians— que s'ofegaren al mar Roig, i un nodrit etcètera, en què podem trobar, també, el nombre de passos que va fer Crist des de l'Hort de Getsemaní fins al Calvari —6.265 i mig! - o el nombre de les vergades que va rebre: 5.490, un nombre que va ser revelat a santa Brígida. De manera que, per a Salt, si s'han pogut esbrinar tantes coses que eren poc previsibles que fossen conegudes, «buscando historias antiguas y manuscriptos autenticos» i per això "an sacado libros nuevos», ell afirma que «rebolviendo librerías antiguas, e sacado el libro de mi padre san Onofre. Porque desde el año mil quinientos y noventa que por mi devoción procuré con alguna curiosidad saber la historia, vida y milagros del santo de mi nombre, asta el dia presente», i passa a citar —només dóna el nom» tot una allau d'autors i de materials que, en teoria, hauria consultat. ${ }^{7}$ De més relleu és el fet que es detinga en una sèrie de textos que, sens dubte, aporten més dades per al coneixement de les fonts de Salt, especialment perquè són textos de l'àrea lingüística catalana i, a més, d'un evident interès. Així, ens diu que

el muy illustre y reverendíssimo señor don Onofre Reart, meritíssimo obispo de Girona, mi señor, me onró con ciertos manuscritos de unas meditaciones de la vida de san Onofre, que para todos los dias de la semana havía compuesto el muy religioso padre don Onofre Illés, monge cartuxo de Montalegre. El muy reverendo padre don Onofre Ripoll, prior del célebre convento de Vall de Cristo me comunicó un manuscrito de la vida de san Onofre en lengua lemosina, que fue del rey don Martín, fundador de aquel convento. El doctor Blay Navarro, padre de la buena teología y de los que se pueden llamar teólogos consumados, me dexó trasladar otro manuscrito famoso de la historia de san Onofre. Los muy reverendos, doctos y santos padres del singular convento de San Onofre de Valencia también me hizieron caridad de comunicarme dos manuscritos: y el uno era trasladado de lengua egypcíaca —eredado de la librería del gran duque de Segorve—; y el otro, muy antiguo, del

7. M’estalvie de reproduir, ací, els més de trenta noms que dóna, a més de «breviarios», «missales antiguos, martyrologios y librerías viejas» (Salt 160: Prólogo... s.p.). 
propio monasterio. $\mathrm{Y}$, assí mesmo me dieron un officio que sus paternidades rezan, del santo, compuesto por el padre maestro fray Luys Martín, hijo del mismo convento. Asta de Roma me imbió el doctor Gabriel Salt, mi señor y tío, canónigo de Tarragona, una famosa oración, sermón y otros papeles pertenecientes a la vida de san Onofre. Y yo, que de mochacho e guardado perpetuamente un libro anónimo de la vida de mi santo, impresso en Valencia, a veynte de deziembre, 1501.

Més enllà de la identificació possible de part d'aquests manuscrits i textos referenciats, ara ens interessa l'al-lusió ja esmentada al «libro anónimo» que identifiquem amb l'edició valenciana que hem comentat anteriorment, atès que ens convé veure fins a quin punt Salt va tenir en compte aquella font i com la va usar en la seua obra.

En aquest sentit, cal remarcar que la lectura de la Historia de sant Onofre del prior del Bon Succés mostra ben clarament que, més enllà dels punts de contacte argumentals o d'alguns detalls concrets ineludibles i esparsos, l'anònima Vida de sanct Honofre va ser usada profusament per Salt a partir d'un determinat moment del seu relat, com ara veurem.

En efecte, l'obra d'Onofre Salt s'estructura en dues parts. A la Primera (f. 1-75), Salt narra pràcticament tota la vida del sant. Això sí: incideix molt en la seua reialesa: el pare d'Onofre, el rei Teodoro, té un paper important en la infantesa del sant $\mathrm{i}$, quan aquell mor, serà Onofre qui el succeirà com a rei d'Hongria (cap. 1-12). Ja jurat rei (cap. 13), Onofre és perseguit i va a l'exili, on busca refugi en la vida monàstica (cap. 14-17). Això permet a l'autor dedicar els capítols següents als "principios y antigüedad de la vida religiosa y monástica» (cap. 18) i a parlar de les diferents formes de vida monacal i eremítica (cap. 1920) i, més concretament, dels anacoretes (cap. 21) i hermopolis (cap. 22), orde on Onofre pren els hàbits i on comença ràpidament a destacar per les seues virtuts (cap. 23-24), que són de seguida mostrades com a modèliques per a l'educació dels novicis, que han d'aprendre dels monjos més vells (26-32). Onofre, que busca respostes a les seues inquietuds espirituals, prompte decideix fer-se anacoreta i és escollit abat (33-34). Salt ens mostra, tot seguit, la cura d'aquell respecte dels seus fills de religió i com alguns d'aquests volgueren matar l'abat Onofre, que se salva per la revelació divina i perdona els enemics, però que el porta a abandonar el monestir i a buscar la solitud del desert (cap. 35-41), on comença una nova vida que en tot moment és proveïda per Déu, amb diferents prodigis (cap. 42-49). Acaba aquesta part amb una reflexió sobre els avantatges de la vida solitària d'Onofre per damunt de la dels gentils (cap. 50).

La Segunda parte s'estructura en 50 capítols més (f. 78-154) i s’inicia amb la revelació de Déu a Pafnuci — monjo que s'encarregarà de narrar la vida d'Onofre-, el qual se'n va al desert a buscar el sant (cap. 1-2). Pafnuci assisteix a "parte de las maravillas que Dios azía a sus santos anacoretas» (cap. 3) i troba el monjo Timoteu i, després, sant Onofre, el qual el porta a la seua cel.la i, poc més tard, li revela la seua pròxima mort, cosa que entristeix Pafnuci (cap. 4-11). 
Onofre Salt aprofita llavors per fer-nos veure que els sants poden alcançar favors de la divinitat (cap. 12-13) i sant Onofre se'ns mostra fent una devota oració, per a ell i per a tots, just abans de morir (cap. 14). Cal advertir que aquesta oració segueix a grans trets la que es conté a la vida anònima valenciana, l'amplifica i la retalla en alguns punts $i$, per tant, fa versió en castellà de l'original catalana de l'edició del Xvi, encara que, segurament — com ell mateix adverteix en nota marginal—, ${ }^{8}$ degué tenir davant altres versions, com es pot veure tot seguit:

8. Salt (1620: 102v.) afirma: «Esta oración dixo nuestro padre san Onofre, según lo escriven graves doctores» i, al marge, indica: «El don Cristóval Alemán, jurisconsulto; monseńor Paulo Regio; Bolufer; la Historia anónima valenciana y los manuscritos.». 
Molt alt e poderós Senyor, lo qual neguna persona en aquest món pot ab ulls corporals veure, lo poder del qual hom no poria pensar, la glòria del qual és inefable e la misericòrdia del qual és sens fi. A tu, Senyor, ador; a tu, Senyor, benehesch; a tu, Senyor, loe; a tu, Senyor, suplique e pregue, lo qual yo he amat per tal! Senyor, puix cride a tu, hoges-me! Car, Senyor, est molt gran! Per ço, Senyor, t'é servit y serviré e t'é loat y loaré ab la mia ànima, car tu prenguist guarda de la mia humilitat e posist guarda als meus peus. E per ço, Senyor, defensa'm de l'enemich diable e vinga sobre mi la tua misericòrdia, car la mia ànima stà molt tribulada, ara que exir vol del meu cors. E prech-te, Senyor, que lo diable no m'apareixca ni.m sia contrari, ni.l veja ni-m vinga davant. Oh, Senyor, hages mercé de mi, per tal que aquella serpent cruel e mala no.m puga en res noure e que la mia ànima no veja aquelles scuredats e infernals figures, les quals són molt horribles! Supplich-te, Senyor, que tu la rebes ab los teus sants àngels, qui són complits de pau, e aquella, per ta infinida pietat y misericòrdia, vulles col-locar en la tua sancta e per tostemps duradora glòria. Encara, Senyor, te demane e supplique, per la tua pietat e misericòrdia, que hajes mercé de mi e del teu poble cristià, e que hoges les lurs pregàries e que perdones tots los peccats de aquells qui faran festa e memòria de mi o faran offerta per la mia honor, e per reverència del teu nom, o donaran a menjar a algun pobre de ço de lur propi, que tu, Senyor, los hoges quand ells a tu recorran e.ls perdones tots lurs peccats. Encara, Senyor, si alguna persona starà en alguna angústia, axí com de presons e de altres tribulacions, o en ira de senyor o de jutge o de altra persona e a tu cridarà e, invocant, dirà: "O, senyor Déu! Tu, poderós, per los mèrits del teu humil servidor, Onofre, hajes merçé de mi”, prech-te, Senyor, que sens triga alguna hojes lurs pregàries e.ls compleixques les lurs peticions, car tu, Senyor, est beneyt e loable per tostemps. Amén.
Muy alto y poderoso señor, a quien ninguna criatura humana puede con ojos corporales ver, cuyo poder es incomparable, misericordia infinita y sabiduria immensa. A ti solo llamo, que tomaste a tu cargo la guarda de mi umildad y pusiste la ley de tu santo Evangelio, como puiguelas a mis pies, para que mis passos fuesen nivelados con la regla de tus santos mandamientos, por lo qual umilmente te ruego me defiendas del enemigo. Venga sobre mi tu misericordia, porque mi alma está muy atribulada aora que por tu orden quiere despedirse del cuerpo. Ruégote, Señor, que no vea el enemigo orrible, en la ora de mi muerte. Suplícote hayas misericordia de mi, para que la serpiente dańada no pueda hazer mella en mi alma. Recíbeme por los méritos de tu santíssima Pasión y dame reposo entre los que gozan del perpetuo descanso en tu santo reyno. Ten misericordia de todo el pueblo cristiano; oye sus rogativas y perdona los que arán memoria y fiesta de mí o darán ofrenda por mi amor y limosna a tus pobres. Dales gracia para que no les falte tu amor y caridad; líbrales de rayos, truenos y fuego, de cárcel, tribulación, ira de su señor y juez, y de qualquier otra adversidad que por mar o tierra padecieren. Dales auxilio y favor para que, acudiendo a ti por verdadera penitencia, les oyas y condeciendas con sus justas peticiones, pues tú, Señor, eres bendito y loable por todos los siglos. Amén.?

\section{El tex es troba a Salt (1620: 102).}


Retornant al desenvolupament de l'obra, Pafnuci, vist que la mort de sant Onofre és inevitable, desitja quedar-se en la seua cel.la; però el sant no ho permet (cap. 15). Rere una reflexió general sobre com Déu «se a mostrado maravilloso en las muertes de los santos», (cap. 16), Salt narra la mort de sant Onofre i els prodigis que s'esdevingueren posteriorment i que va contemplar Pafnuci, el qual, després d'aconhortar-se, dóna sepultura prodigiosament al cos del sant (cap. 17-22). Pafnuci, enviat de retorn a Egipte per Déu, passa per diferents episodis i arriba al seu destí (cap. 23-30). Tot seguit, Salt ens mostra la persecució de Dioclecià i Maximià contra els cristians d'Egipte i com Pafnuci els defensa, per la qual cosa és pres i turmentat (cap. 31-33); però aquell aconsegueix vèncer i convertir, de retruc, molts infidels (cap. 34-36). Novament turmentat per Arrià (cap. 37), Pafnuci torna a eixir victoriós i converteix més infidels (cap. 38). Arrià, enfurit, mana llançar-lo a un riu i encara que Pafnuci se'n salva, morirà poc després (cap. 39-40). Els monjos egipcis — que saben la història de sant Onofre per via de Pafnuci- decideixen anar a buscar el cos de l'anacoreta, que el troben i el porten a Egipte (cap. 41-42). De camí, sant Onofre obra un miracle, quan ressuscita dos morts (cap. 43). Tot seguit, l'autor fa un salt en el temps i comença a parlar-nos del «famoso convento de San Onofre de Roma» (cap. 44) i, després, del monestir de Pisa (cap. 45), d'una capella a Florència (cap. 46), la capella del convent de Pedralbes, a Barcelona (cap. 47), una altra a Girona (cap. 48), l'ermita de Museros, prop de València (cap. 49), tot acabant amb el relat del retaule dedicat a sant Onofre que anà a parar al convent dels Predicadors de València (cap. 50).

El volum acaba amb una oració a sant Onofre (s. p.) «la qual pueden dezir y rezar sis devotos cada dia, para alcançar por su medio el favor divino», que no té res a veure amb la que es conté a l'opuscle de principis del XVI, anònim i valencià. Una relació major i més evident podem establir en altres episodis que comentarem tot seguit, i més enllà d'alguns fragments en què la influència textual de l'anònim es deixa sentir lleugerament. ${ }^{10}$

10. A tall d'exemple, oferim, ací, la mostra següent: A) Versió de l'anònim valencià: «aparech-me un àngel. Dix-me: - No vulles plorar, Pannúcio, ans hages en tu gran alegria e molt gran plaer per tal com tu est stat digne de veure tant glorioses e celestials maravelles; e hix de açí e ves-te'n en Egypte e preÿca e digues totes les coses que has vistes e hoïdes, axí com te dix aquell nostre amich Onofre; e nostre senyor Jesucrist te endreçarà e.t farà sanct en la sua glòria per la sua pietat e haurà mercé de tu e tostemps te endreçarà en tos camins.» B) Versió de Salt (1620: 116v.): «le apareció el ángel del Señor y le dixo: - No llores, Pafnuncio. No te aflijas ni te atribules. Está alegre y contento, pues Dios te a echo digno que pudieras ver lo que as visto: tenlo en la memoria y alábale. Lo que aora te manda es que salgas de aqueste lugar y te vayas a las provincias de Egypto, predicando a los monges y retirados solitarios, y a los demás fieles de la iglesia, y prediques lo que a obrado con su siervo, Onofre, y con los demás ermitaños y anacoretas que has visto y verás, para que todos queden edificados y sirvan con nuevo brío a su Divina Magestad. Él te guarde y tenga misericordia de ti, dirigiendo tus caminos a su santo servicio y queda en paz.». 


\section{A tall de conclusions}

Si bé és cert que s'aparta bastant en determinats capítols — per exemple: sant Onofre ressuscita dos homes de camí a Bohèmia, en l'anònim (Escartí 2014: 61), i ho fa de camí a Egipte, en Salt (1620: 140-141v.); o, encara, el prior del Bon Succés ens parla d'un "famoso convento de San Onofre de la ciudad de Roma» (Salt 1620: 141v.-143v.) que no apareix en l'anònim-, no és menys cert que es manté més fidel al traçat del text valencià a partir del capítol 45. Així, en aquest capítol (De un monasterio que edificaron los de Pisa en onra del bendito san Onofre) es recull la notícia oferida per l'anònim de tal manera que el resultat final quasi no s'assembla en la seua fesomia externa, tot i que l'esquelet del relat es manté (Salt 1620: 143v.-144v.). Per la seua banda, al capítol següent (De una famosa capilla que edificaron los de la ciudad de Florencia en onor del bendito san Onofre), si bé passa pràcticament el mateix que a l'anterior, en alguns fragments és més facil reconèixer la font: huna bellíssima capella / una sumptuosa capilla; tots anys, en la sua gloriosa festa, per tota la ciutat y per los circumvehins s'i fa y solemniza gran festivitat y alegria / todos los años el dia de su fiesta (...) la festejavan para que asi los de la comarca acudieran a ella; la comunitat féu fer crida que per honor y reverència de sant Onofre, en lo dia de la sua gloriosa festa, que.s celebre / los magistrados y regidores de la misma ciudad (...) determinaron celebrar su fiesta (...) con publico pregón; donaria per joya quatre canes de finíssima scarlata (...) qui ab son cavall millor y més corregués en lo camp del cors / prometían dar una rica joya y aventajado premio, con ocho varas de finissima grana al que saliendo a correr con su cavallo se aventajasse a los demás; un cavaller natural de la ciutat de Pisa, lo qual era molt devot del benaventurat sant Onofre / sucedió que un cavallero pisano (...) con el amor que al santo tenía / féu oració a Déu e a sant Onofre (...) de continent que la haja guanyada, vote y promet a tu, Senyor, la presentaré al benaventurat sant Onofre / encomendándose muy de veras al bendito san Onofre, le prometió que si ganava la joya se la presentaría al bendito santo en su proprio convento de la ciudad de Pisa; secretament mès-se en lo camp del cors, ab los altres qui eren ben encavalcats, ab cavalls ben abillats e ben corrents / llegó la hora de salir al cozo. Salieron los cavalleros florentines con la pujança y gallardía que avemos dicho y el devoto cavallero pisano (...) salió disfraçado; E plagué a nostre senyor Déu demonstrar la sua gràcia / Quiso dar Dios a entender, se'n tornà en Pisa, en lo dit monestir de Sanct Onofre / se partió luego para su ciudad. Llegó al monasterio de San Onofre; per major gràcies reté a Déu lo chich roçí e aquell al monestir de Sant Onofre donà, perquè servís a les necessitats del dit monestir I hizole gracias (...) con ofrecerle el priz y joya que avia ganado, le dio también el cavallo para el servicio del convento. ${ }^{11}$

11. Els fragments de l'anònim provenen d'Escartí (2014); els de Salt, de l'edició del 1620: (144v.146r.). 
Com es veu, a més de l'entramat de la narració, podem resseguir clares influències de la versió valenciana. I el mateix passa, també, pràcticament, als quatre capítols següents, que clouen el treball de Salt i que segueixen —més o menys - sengles quatre apartats que trobem a l'anònim, quasi amb idèntics títols, però amb una lleugera alteració en l'ordre d'aparició. Així, el capítol 47 - Edifica el convento de Pedralbas de Barcelona al bendito san Onofre una capilla- (Salt 1620: 146-147v.) amplifica el que a l'anònim s'intitula Miracle de un mercader de Barsalona, qui per mèrits de sant Onofre fon delliure del perill de la mar (Escartí 2014: 63-64); i el capítol 48 - Fúndase en la ciudad de Girona una capilla a onor del bendito san Onofre y magnifica Dios sus devotos- (Salt $147 \mathrm{v} .-148 \mathrm{v}$.) fa la mateixa operació amb el que a l'anònim valencià porta per títol Miracle fet en la ciutat de Girona, a un capellà devot de sant Onofre (Escartí 2014: 65). El capítol 49, però, prové sens dubte de l'historiador valencià Diago, que relata el cas a la seua Historia de la provincia de Aragon de la orden de Predicadores (1599: 2, 282v.-283r.), i conjuga notícies de l'anònim, com quan inclou el Miracle fet per lo benejt sant Honofre a un religiós de la ciutat de València, al final del seu capítol XLIX, en un apartat que porta la següent anotació al marge esquerre: Religioso de Valencia se da por devoto de san Onofre. El capítol L (Del angelical retablo que en esta ermita ay del bendito san Onofre, y cómo fue dada para convento de la orden de Predicadores), per la seua banda, recolliria la tradició que es documenta ja a l'anònim - Miracle de la ymatge de sant Honofre en la ciutat de València - (Escartí 2014: 66) i que apareix també més ampliada a Diago, d'on segurament la va prendre Salt.

Comptat i debatut, si la Vida de sanct Honofre, anònima, de publicada a principis del xvi tal com la coneixem ara, és un clar exemple de la construcció d'un relat hagiogràfic per acumulació i, malgrat les fonts tan disperses i els diferents moments de la seua confecció, el resultat és suficientment unitari i compacte perquè encara faça de bon llegir i ens permeta l'estudi de la creació «literària» a finals de l'edat mitjana, la seua connexió evident — molt camuflada, de vegades - amb la Historia de la maravillosa vida, angélica conversación y preciosa muerte del glorioso san Onofre, rey, anacoreta y confessor, d'Onofre Salt, ens permet veure que aquell text que va estar construït a base de "pedaços», a la fi, a començaments del barroc, va esdevenir un pedaç més en la cadena de transmissió de la biografia més o menys fantàstica del sant anacoreta Onofre. 


\section{Bibliografia}

Aguiló i Fuster, Marià, Catálogo de las obras en lengua catalana impresas desde 1474 hasta 1860, Madrid, Sucesores de Rivadeneyra, 1923.

Arronis Llopis, Carme, La vida de la sacratíssima verge Maria de Miquel Peres (1494), Barcelona / Alacant, Institut Interuniversitari de Filologia Valenciana / Publicacions de l'Abadia de Montserrat, 2015a.

—, "Santa sobre totes les santes”. La Verge Maria com a model de santedat femenina: la proposta de Miquel Peres», Medievalia, 18/2, 2015b, 65-95.

—, «Dos lecturas de la vida de María: la Vita Christi de Isabel de Villena y la Vida de la sacratíssima verge Maria de Miquel Peres», Mirabilia, 22 (2016), 128-153.

Barniol, Montserrat, «El culto a san Onofre en Cataluña durante los siglos XIV y XV", dins El culto a los santos: cofradias, devoción, fiestas y arte, San Lorenzo de El Escorial, Instituto Escurialense de Investigaciones Históricas y Artísticas, 2008, 177-199.

BITECA. Bibliografia de Textos Catalans Antics [on line], University of California Berkeley (1997- ). <http://sunsite.Berkeley.edu/PhiloBiblon/BITECA/1299.html> [data de consulta: 25/12/2016].

Blasco de Lanuza, Vincencio, Historias ecclesiásticas y seculares de Aragón..., Tom I, Saragossa, Juan de Lanaia y Quartanet, 1622.

CANET, José Luis, «Hagiografía valenciana (1470-1600)», Les cahiers de Framespa, 1 (2005). <https://framespa.revues.org/411?lang=es> [data de consulta: $25 / 12 / 2016]$.

Diago, Francisco, Historia de la provincia de Aragon de la orden de Predicadores, desde su origen y principio hasta el año de mil y seyscientos, Barcelona, Sebastian de Cormellas, 1599.

EsCARTí, Vicent Josep, Sobre la vida i els miracles de sant Onofre, anacoreta, segons la versió anònima publicada a València a començaments del segle XVI, València, Espirelius, 2014.

—, «Edició filològica i breu comentari de La vida de sanct Honofre, publicada a València a principis del segle XvI», Mirabilia / MedTrans, 1, 2015, 176-225 [data de consulta: 25/12/2016].

Ferri Chulio, Andrés de Sales, Mariología Patronal del Camp de Morvedre, Sagunt, Publicaciones de la Caja de Ahorros y Socorros de Sagunto, 1983.

Fuster, Just Pastor, Biblioteca valenciana, València, Josep Ximeno, 1827.

Galiana, Lluís, "Carta», dins Ros, Carles, Diccionario valenciano-castellano, València, Benet Montfort, 1764

Gisbert Terol, Ana i Ortells Pérez, M. Lutgarda, Catálogo de obras impresas en el siglo XVI de la Biblioteca General e Histórica de la Universidad de Valencia, València, Conselleria de Cultura, Educació i Ciència, 1992.

Hernández Serna, Joaquín, «El manuscrito 13 de la Biblioteca de Catalunya: Comença del benaventurat sant Honoffre la sua santa e virtuosa vida», Estudios Románicos, 8-9 (1993-1995), 185-262. 
—, «Emisión y recepción de textos hagiográficos», dins Littera scripta in honorem Prof. Lope Pascual Martínez, Múrcia, Universidad de Murcia, 2002, 477-520.

López Quiles, Antoni, Literatura i espiritualitat. Aproximació a l'obra de Corella com a resposta davant Déu i l'home, València, Institució Alfons el Magnànim, 207.

López Quiles, Antoni i Puig Gisbert, Abel, Ensenyar, commoure i adelitar. Notes de propedèutica per a rellegir Corella, Catarroja, Periferric Edicions, 2014.

Lorente Pérez, Vicente, «La provincia española de los Siervos de María, de 1623 a 1848", Studi Storici de l'Ordine dei Servi di Maria, LXIV-LXV (2014), 149-188.

Martínez Romero, Tomàs, «Miquel Péreç i la posteritat de Corella», Revista de Literatura Medieval, 24 (2012), 193-210.

Madurell Marimón, Josep Maria, «Llicències reials per l'edició de llibres piadosos catalans (1563-1704)», Analecta Sacra Tarraconensis, 28 (1955), 379-383.

Martos, Josep Lluís: «La Vida de Sancta Bàrbara del Jardinet d'orats: Joan Roís de Corella o la recepció de la seua obra", dins Actas del VIII Congreso Internacional de la Asociación Hispánica de Literatura Medieval, vol. II, Santander, Asociación Hispánica de Literatura Medieval, 2002, 1269-1287.

Pastor Briones, Vicent, "La vita aspera de sant Onofre: anàlisi i edició», dins Miscel.lània Albert Hauf, 4, Barcelona, Publicacions de l'Abadia de Montserrat, 2012, 5-30.

Ribelles Comín, Josep, Bibliografía de la lengua valenciana, vol. II, Madrid, Tipografía de la Revista de Archivos, 1929.

Rodríguez, Josep, Biblioteca valentina, València, Josep Tomàs Lucas, 1747.

Roís de Corella, Joan, Psalteri, a cura de J. L. Martos, València, Institució Alfons el Magnànim, 2013.

—, Obra completa, a cura de V. J. Escartí, València, Institució Alfons el Magnànim, 2014.

SALT, Onofre, Historia de la maravillosa vida, angélica conversación y preciosa muerte del glorioso san Onofre, rey, anacoreta y confessor, Barcelona, Esteve Lliberós, 1620.

Serrano Morales, J. Enrique, Reseña histórica en forma de diccionario de las imprentas que han existido en Valencia desde la introducción del arte tipográfico en España hasta el año 1868, València, F. Doménech, 1898-1899.

Valldecabres Rodrigo, Rafael, Vida de sant Onofre, Quart de Poblet, Ajuntament de Quart de Poblet, 2004.

Vida de sancto Honofre, València, Vicent García Editores, 2004 (ed. facsímil).

VIllarroya, Josep, Apuntamientos para escribir la historia del derecho valenciano y verificar la perfecta traducción de los fueros, València, Josep d'Orga, 1804. 
Wittrin, Curt, De la traducció a la creació literària, València / Barcelona, Institut Interuniversitari de Filologia Valenciana, 1995.

XImeno, Vicent, Escritores del reyno de Valencia, 2 vols., València, Josep Estevan Dolç, 1747-1748. 